\title{
SEAKEEPING OF A FAST DISPLACEMENT CATAMARAN
}

\author{
Vasilij Dyachkov ${ }^{1}$, Jurij Makov² \\ ${ }^{1}$ Klaipèda University, Bijūnu g. 17, LT-91225 Klaipèda, Lithuania.E-mail:vasilijd@takas.lt \\ ${ }^{2}$ Kaliningrad State Technical University, Sovietsky prospect 1, 236000 Kaliningrad, Russia. \\ E-mail:makov@klgtu.ru
}

Received 2004-10-16; accepted 2004-12-03

\begin{abstract}
The paper presents a complex method for the calculation of pitch and heave of a fast displacement catamaran. It incorporates speed factors, interference of catamaran hulls, stabilization factors and possibility to apply different stabilization cases including a stabilizer activation possibility. In the method the possibility to evaluate catamaran motions in irregular waves is also included. On the base of the presented method the computer program is developed and applied to calculate seakeeping characteristics of a catamaran stabilized with a fore passive wing. The results of calculation are in good compatibility with the experimental model tests of this catamaran in irregular waves. The calculation method could be effectively applied in the design stage of fast displacement catamarans or of fin stabilizers determining their effectiveness.
\end{abstract}

Keywords: catamaran, pitching, heaving, fin stabilizers, calculation method.

\section{Introduction}

Fast displacement catamarans are taking lead among the world's speed vessels. The fast growth of popularity of fast catamarans can be explained by their advantages. Comparing to relative displacement monohull vessel catamarans have larger deck area, smaller draft, greater speed and significant initial stability $[1,2]$. But despite all advantages of catamarans their usage is mostly limited by regional trips of respectively small distances. One of the reasons of limited catamaran usage is their seakeeping. Because of a narrow form of the hulls the seakeeping qualities (pitching and heaving) are the same as of a monohull vessel and even worse [3, 4].

Ship oscillations lead to a number of negative consequences and influence on ship's seakeeping and working qualities. Its undesirable and even dangerous consequences pertain: ship's turning over possibility under the influence of external fixing loads; deck splashing and pouring, reduction of velocities of the move and deterioration to controllability, appearance of the additional loads in constructions of the hull and deterioration of the habitability conditions on the ship. Water penetrates through a ventilation system into the hull, puts out of operation mechanisms and equipment and spoils cargoes [5, 6]. Oscillations can cause pain- ful sensations - sea-sickness. The main reason of seasickness is a physiological influence of angular and linear accelerations upon a human organism. Vertical accelerations and their changes are the most unpleasant. Especially sea-sickness is developing in the case when vertical accelerations seek approximately $0,1 \mathrm{~g} \approx 1 \mathrm{~m} / \mathrm{s}^{2}[7,8]$. It's a fact that the main reason for the reduction of velocities of the move is ship heaving and pitching which leads to foreship pouring and intense slamming [9].

Hereupon moderating of ships heaving and pitching is to be always useful. Therefore it required studying to make catamaran pitching and heaving more stable.

\section{Problem analysis}

Ship heaving and pitching can be reduced as follows:

- Optimal (from the point of view of oscillations) choosing of a hull shape (U-form frames in a fore ship lead to greater pitching and heaving than $\mathrm{V}$ form frames;

- optimal accomodation of the load;

- rational ship maneuvering changing the motion speed and course angle to the running up waves; 
- using the facilities for local stabilization of cabins, posts, mechanisms etc.;

- using the facilities for global ship stabilization.

The first and partly the second items can be solved in the complex in the design stage of the ship; the third and partly the second items are determined by the ship working conditions; the fourth item solves stabilization problem only partly. And only using the facilities of global ship stabilization will solve a ship stabilization problem in total [10].

To reduce the amplitudes of heaving and pitching stabilizers should provide moderating these type of oscillations approximately 5-6 times, however this requires such a great effort that it is becoming not possible to implement. Therefore it is reasonable in respect of heaving and pitching not to go beyond double reduction, taking into account the possibility of appearance of vertical accelerations greater than $0,1 \mathrm{~g}$.

Habitability conditions on the ship are defined not only by home comfort for passengers and crew. They also include a row of other elements which directly depend on oscillations. For example, conditions of the service of ship mechanisms and systems. The less are oscillations, the better conditions for errorfree performance of mechanisms and their service [11].

Stabilizers are intended for the improvement of ship seakeeping characteristics as follows:

1. Navigability, in the way of reducing oscillations and creating favourable habitability conditions for passengers and crew;

2. Stability of course and controllability of a ship in rough sea and under storm conditions.

Besides, stabilizers promote reduction of ship splashing and pouring.

Stabilizers create a variable on sign and value stabilizing moment which acts in the plane of frames and partly compensates rough sea disturbing moment of ship oscillations, in consequence of which the oscillation amplitudes, velocities and accelerations are also reduced [8].

Scientists all over the world are solving the problems of seakeeping for fast displacement catamarans.

One of the most used and most effective nowadays method of pitch and heave controlling is using of fin stabilizers in a bow and in a stern part of a ship. The effectiveness of such method for fast displacement catamarans till now is only possible to determine by model tests or by natural experiments [12].

Initially fin stabilizers on catamarans were used for the reduction of water resistance. Practical and successful fin system was patented and called Hysucat (Hydrofoil supported catamaran). Fin systems Hysucat were developed in the process of systemati- cal towing tests in towing tank and with the help of ship gliding theory [13].

The interest to seakeeping of catamarans especially to the reduction of their pitching and heaving originates from the end of the $20^{\text {th }}$ century. E. M. Kogan $[3,4,14]$ and J. M. Mastushkin were treating hydrodynamic characteristics of catamaran supplied with fin pitching and heaving and have developed theoretical analysis methods for treating catamaran oscillations and reduction of pitching and heaving for catamaran with fin [15]. One of the methods was developed according to the catamaran "Experiment" that was built in the 80's of the past century. This catamaran was supplied with a fore fin stabilizer and was successfully tested in rough sea [16]. But this method was created for catamarans with moderate velocity of the move and can not be applied to the analysis of seakeeping of fast displacement catamarans.

Nowadays the attention of researchers is more directed to the improvement of methods for the forecasting of navigability and popularity, and to design area - to catamarans with fins $[17,18]$. Quite high seakeeping qualities of these ships can be reached by using automatic controlled fin stabilizers. Nevertheless, the results of applying controllable fin stabilizers to fast displacement catamarans as it was mentioned above is only possible to determine in an experimental way.

Therefore in this article the authors present the method which gives possibility to evaluate seakeeping characteristics of a fast displacement catamaran in regular and irregular waves either with applied stabilization devices or without them.

\section{Methodology}

Analyzing seakeeping qualities of a catamaran we will start from the basic ship pitching and heaving theory in regular waves. As it was mentioned before, ships of a catamaran type, thanks to hull clearance have significant initial stability, whereas pitching and heaving of these ships in rough sea are quite large and require additional action for their reducing. The method that will be presented below is based on the calculation for one hull of a catamaran including all necessary factors and coefficients that describe catamaran oscillations in regular waves. Founding on the said we will write pitching and heaving equations [19]:

$\left\{\begin{array}{l}a_{11} \ddot{\zeta}_{g}+b_{11} \dot{\zeta}_{g}+c_{11} \zeta_{g}+a_{12} \ddot{\psi}+b_{12} \dot{\psi}+c_{12} \psi= \\ F_{1} \cos \omega_{k} t+F_{2} \sin \omega_{k} t ; \\ a_{22} \ddot{\psi}+b_{22} \dot{\psi}+c_{22} \psi+a_{21} \ddot{\zeta}_{g}+b_{21} \dot{\zeta}_{g}+c_{21} \zeta_{g}= \\ M_{1} \cos \omega_{k} t+M_{2} \sin \omega_{k} t ;\end{array}\right.$ 
here $\omega_{k}=\omega-k \cdot v \cdot \cos \beta_{v}-$ apparent frequency of the wave $(1 / \mathrm{s})$, where $\omega$-radial frequency of the wave $(1 / \mathrm{s}), v-$ ship speed $(\mathrm{m} / \mathrm{s}), \beta_{v}$ - angle between ship motion direction and direction of the spreading the waves (deg).

$\zeta_{g}-$ ship's vertical shift coordinate $(\mathrm{m}) ; \psi-$ ship's trim (rad);

$a_{i j}, b_{i p} c_{i j},(i, j=1,2)$ - resistance and added mass factors, $F_{1}, F_{2}$ - disturbing forces (N) and $M_{1}, M_{2}-$ disturbing moments $(\mathrm{N} \cdot \mathrm{m})$, which for catamaran, moving with speed $v$ will be as follows:

$$
\begin{aligned}
& a_{11}=D / g+\Delta M, \quad b_{11}=v_{\zeta}, \quad c_{11}=\gamma S_{k}, \\
& a_{12}=\Delta M x_{1}, \quad b_{12}=v_{\zeta \psi}-v \Delta M, \quad c_{12}=\gamma S_{k} l-v v_{\zeta}, \\
& a_{22}=I_{y}+\Delta I_{y}, \quad b_{22}=v_{\psi}+\frac{v^{2}}{\omega^{2}} v_{\zeta}, \quad c_{22}=D H-v^{2} \Delta M, \\
& a_{21}=\Delta M x_{1}, \quad b_{21}=v_{\zeta \psi}+v \Delta M, \quad c_{21}=\gamma S_{k} l+v v_{\zeta},
\end{aligned}
$$

here $D$ - displacement tonnage of one hull of catamaran $(\mathrm{N}) ; g$ - acceleration of gravity $\left(\mathrm{m} / \mathrm{s}^{2}\right) ; H$ - large (longitudinal) metacentric height (m); $\gamma$-water specific gravity $\left(\mathrm{N} / \mathrm{m}^{3}\right) ; S_{k}-$ area of a load waterline of one hull $\left(\mathrm{m}^{2}\right) ; l=x_{g}-x_{c}$ - distance between center of waterline area and center of gravity of catamaran (m); $x_{g}$ - absciss of center of gravity (m); $x_{c}-$ absciss of center of waterline area (m); $I_{y}$ - ship's mass moment of inertia $\left(\mathrm{kg} \cdot \mathrm{m}^{2}\right)$;

According to the hypothesis of the flat sections we will find equation components as follows: $\Delta M=\int^{-L_{a}} \mu_{0}(x) d x-$ added water mass when heaving $(\mathrm{kg})$; $L_{f}$

$\Delta M x_{1}=\int_{L_{f}}^{-L_{a}} x \mu_{0}(x) d x-$ added water mass static moment about center transverse axis $(\mathrm{kg} \cdot \mathrm{m})$;

$\Delta I_{y}=\int_{L_{f}}^{-L_{a}} x^{2} \mu_{0}(x) d x$ - associate moment of inertia of added water mass $\left(\mathrm{kg} \cdot \mathrm{m}^{2}\right)$;

$v_{\zeta}=\int_{-L_{a}}^{a} v_{0}(x) d x$ - heaving resistance factor $(\mathrm{kg} / \mathrm{s})$;

$v_{\zeta \psi} \stackrel{L_{f}^{-}}{=} \int_{L_{f}}^{L_{a}} x v_{0}(x) d x$ - resistance factor, taking into account mutual influence of pitching and heaving $(\mathrm{kg} \cdot \mathrm{m} /$

s);

$\left(\mathrm{kg} \cdot \mathrm{m}^{2} / \mathrm{s}\right)$;

$v_{\psi}=\int_{\left.L_{f}^{2} / \mathrm{s}\right)}^{-L_{a}} x^{2} v_{0}(x) d x-$ pitching resistance factor

Disturbing forces and moments are:

$$
\begin{aligned}
& F_{1}=r_{0}\left(\gamma a_{0}-\omega^{2} a_{0}^{\prime \prime}-\omega b_{0}^{\prime}\right), F_{2}=-r_{0}\left(\gamma b_{0}-\omega^{2} b_{0}^{\prime \prime}-\omega a_{0}^{\prime}\right) \\
& M_{1}=r_{0}\left(\gamma a_{1}-\omega^{2} a_{1}^{\prime \prime}-\omega b_{1}^{\prime}\right), M_{2}=-r_{0}\left(\gamma b_{1}-\omega^{2} b_{1}^{\prime \prime}-\omega a_{1}^{\prime}\right)
\end{aligned}
$$

here $r_{0}$-wave amplitude (m);

Factors of the main part of disturbing for$\operatorname{ces} a_{0}, a_{1}, b_{0}, b_{1}$ are:

$$
\begin{aligned}
& a_{0}=2 \int_{L_{f}}^{-L_{a}} y_{1} \cos k x d x,\left(m^{2}\right) ; \quad a_{1}=2 \int_{L_{f}}^{-L_{a}} x y_{1} \cos k x d x,\left(m^{3}\right) ; \\
& b_{0}=2 \int_{L_{f}}^{-L_{a}} y_{1} \sin k x d x,\left(m^{2}\right) ; \quad b_{1}=2 \int_{L_{f}}^{-L_{a}} x y_{1} \sin k x d x,\left(m^{3}\right),
\end{aligned}
$$

here $y_{1}=y_{0}-\frac{k}{2} S_{f}$, where $y_{0}-$ half breadth of hull of catamaran, measured on the level of load waterline (m); $k=\frac{2 \pi}{\lambda}$-wave number $(1 / \mathrm{m}) ; \lambda$-wave length $(\mathrm{m})$; $x$-distance between treated section and ship's center of gravity $(\mathrm{m}) ; S_{f}$ - wetted frame surface $\left(\mathrm{m}^{2}\right)$.

Factors of diffractional resistance components of disturbing forces $a_{0}^{\prime}, a_{1}^{\prime}, b_{0}^{\prime}, b_{1}^{\prime}$ are:

$$
\begin{aligned}
& a_{0}^{\prime}=\int_{L_{f}}^{-L_{a}} v_{0}(x) \cos k x d x,\left(\frac{k g}{s}\right) \quad a_{1}^{\prime}=\int_{L_{f}}^{-L_{a}} x v_{0}(x) \cos k x d x,\left(\frac{k g \cdot m}{s}\right) \\
& b_{0}^{\prime}=\int_{L_{f}}^{-L_{a}} v_{0}(x) \sin k x d x,\left(\frac{k g}{s}\right) \quad b_{1}^{\prime}=\int_{L_{f}}^{-L_{a}} x v_{0}(x) \sin k x d x,\left(\frac{k g \cdot m}{s}\right),
\end{aligned}
$$

here $v_{0}(x)$ - resistance factor of heaving of flat isolated contour which has form of theoretical frame. This factor is to be found by Salkaev graphs depending on $\beta, \frac{b}{2 d}$ and $\frac{\pi b}{\lambda}$, where $\beta$ - frame block factor, $b$ - breadth of frame on level of load waterline $(\mathrm{m})$ and $d$-ship's draft on load waterline (m) [20].

Factors of diffractional inertial components of disturbing forces $a_{0}^{\prime \prime}, a_{1}^{\prime \prime}, b_{0}^{\prime \prime}, b_{1}^{\prime \prime}$ are:

$$
\begin{aligned}
& a_{0}^{\prime \prime}=\int_{L_{f}}^{-L_{a}} \mu_{0}(x) \cos k x d x,(k g) ; \quad a_{1}^{\prime \prime}=\int_{L_{f}}^{-L_{a}} x \mu_{0}(x) \cos k x d x,(k g \cdot m) ; \\
& b_{0}^{\prime \prime}=\int_{L_{f}}^{-L_{a}} \mu_{0}(x) \sin k x d x,(k g) ; \quad b_{1}^{\prime \prime}=\int_{L_{f}}^{-L_{a}} x \mu_{0}(x) \sin k x d x,(k g \cdot m),
\end{aligned}
$$

here $\mu_{0}(x)$ - added mass factor of heaving of flat isolated contour, which has form of theoretical frame which is also to be found by Salkaev graphs [20].

To evaluate the interference between catamaran hulls and its influence on the pitch and heave of a fast displacement catamaran we should add a figure of added mass which arises from hull interference to the added mass factor. This figure would be sufficient to 
take from the graph made for two flat plates moving one near another [20]. This graph is presented in Fig 1.

Differential equations of the motion of a catamaran moving with speed $v$ when pitching and heaving can be written as follows:

$$
\left\{\begin{array}{l}
\left(\frac{D}{g}+\Delta M\right) \ddot{\zeta}_{g}+v_{\zeta} \dot{\zeta}_{g}+\gamma S_{k} \zeta_{g}+\Delta M x_{1} \ddot{\psi}+\left(v_{\zeta \psi}-v \Delta M\right) \dot{\psi}+\left(\gamma S_{k} l-v v_{\zeta}\right) \psi= \\
r_{0}\left(\gamma a_{0}-\omega^{2} a_{0}^{\prime \prime}-\omega b_{0}^{\prime}\right) \cos \omega_{k} t-r_{0}\left(\gamma b_{0}-\omega^{2} b_{0}^{\prime \prime}-\omega a_{0}^{\prime}\right) \sin \omega_{k} t \\
\left(I_{y}+\Delta I_{y}\right) \ddot{\psi}+\left(v_{\psi}+\frac{v^{2}}{\omega^{2}} v_{\zeta}\right) \dot{\psi}+\left(D H-v^{2} \Delta M\right) \psi+\Delta M x_{1} \ddot{\zeta}_{g}+\left(v_{\zeta \psi}+v \Delta M\right) \dot{\zeta}_{g}+\left(\gamma S_{k} l+v v_{\zeta}\right) \xi_{g}= \\
r_{0}\left(\gamma a_{1}-\omega^{2} a_{1}^{\prime \prime}-\omega b_{1}^{\prime}\right) \cos \omega_{k} t-r_{0}\left(\gamma b_{1}-\omega^{2} b_{1}^{\prime \prime}-\omega a_{1}^{\prime}\right) \sin \omega_{k} t .
\end{array}\right.
$$

The components of these equations are subjects to revision when a catamaran is moving with the relatively large speed, corresponding to Frude numbers of 0,3 . For revision we will use additional forces and moments equations when pitching and heaving, that are written in dependence of derivatives $d C_{z} / d \alpha=C_{z}^{\alpha}$, $d C_{m} / d \alpha=C_{m}^{\alpha}$ and pressure factor $C_{d}[20]$ :

$$
\left\{\begin{array}{l}
\Delta P=\rho v^{2} S_{k}\left(1-\beta_{k}\right)\left(-C_{z}^{\alpha} \psi+\frac{C_{d} L}{2 v} C_{z}^{\alpha} \dot{\psi}+\frac{1}{v} C_{z}^{\alpha} \dot{\zeta}\right) \\
\Delta m=0.5 \rho v^{2} S_{k}\left(1-\beta_{k}\right)\left(-C_{m}^{\alpha} \psi+\frac{C_{d} L}{2 v} C_{m}^{\alpha} \dot{\psi}+\frac{1}{v} C_{m}^{\alpha} \dot{\xi}\right)
\end{array}\right.
$$

here $C_{z}^{\alpha}$ - lifting force factor; can be taken from Fig 2, in dependence of parameters $L / B$ and $F r ; C_{m}^{\alpha}$ - derivative of moment factor on attack angle; can be taken from Fig 3 in dependence of pa-

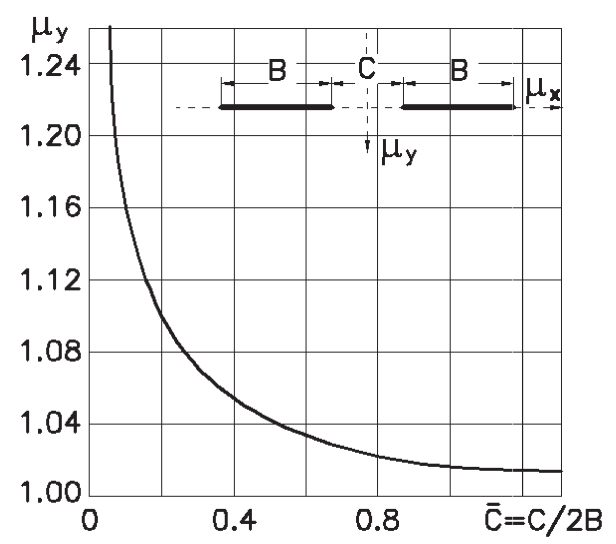

Fig 1. Added mass factor of hull interference rameters $L / B$ and $F r ; C_{d}$-factor of pressure center; can be taken from Fig 4 in dependency of parameters $L / B$ and $F r ; L$ - catamaran hull length on level of load waterline (m); $B$ - one catamaran hull breadth (m); $F r=\sqrt{v / g L}$ - Frude number; $\beta_{k}$ - average hull deadrise angle (deg), which can be found as follows:

$$
\beta_{k}=\frac{\beta_{1} B_{1}+\beta_{5} B_{5}+\beta_{10} B_{10}+\beta_{15} B_{15}+\beta_{19} B_{19}}{B_{1}+B_{5}+B_{10}+B_{15}+B_{19}},
$$

where $\beta_{i}, B_{i}$ - deadrise angle and breadth of $i$ frame on level of load waterline. Combining components of equation (8) with equation (7), we can write differential equations of fast displacement catamaran $(\mathrm{Fr}>0,3)$ pitching and heaving:

$$
\left\{\begin{array}{l}
\left(\frac{D}{g}+\Delta M\right) \ddot{\zeta}_{g}+\left(v_{\zeta}+v_{\zeta z}\right) \dot{\zeta}_{g}+\gamma S_{k} \zeta_{g}+\Delta M x_{1} \ddot{\psi}+\left(v_{\zeta \psi}+v_{\zeta \psi z}-v \Delta M\right) \dot{\psi}+\left(\gamma S_{k} l-v v_{\zeta}-v_{\zeta z}\right) \psi= \\
r_{0}\left(\gamma a_{0}-\omega^{2} a_{0}^{\prime \prime}-\omega b_{0}^{\prime}\right) \cos \omega_{k} t-r_{0}\left(\gamma b_{0}-\omega^{2} b_{0}^{\prime \prime}-\omega a_{0}^{\prime}\right) \sin \omega_{k} t ; \\
\left(I_{y}+\Delta I_{y}\right) \ddot{\psi}+\left(v_{\psi}+v_{\psi m}+\frac{v^{2}}{\omega^{2}} v_{\zeta}\right) \dot{\psi}+\left(D H-v^{2} \Delta M-v v_{\zeta \psi m}\right) \psi+\Delta M x_{1} \ddot{\zeta}_{g}+\left(v_{\zeta \psi}+v_{\zeta \psi m}+v \Delta M\right) \dot{\zeta}_{g}+ \\
\left(\gamma S_{k} l+v v_{\zeta}\right) \zeta_{g}=r_{0}\left(\gamma a_{1}-\omega^{2} a_{1}^{\prime \prime}-\omega b_{1}^{\prime}\right) \cos \omega_{k} t-r_{0}\left(\gamma b_{1}-\omega^{2} b_{1}^{\prime \prime}-\omega a_{1}^{\prime}\right) \sin \omega_{k} t,
\end{array}\right.
$$




$$
\begin{aligned}
& v_{\zeta_{z}}=\rho v S_{k}\left(1-\sin \beta_{k}\right) C_{z}^{\alpha}, \\
& v_{\psi m}=\rho v S_{k}\left(1-\sin \beta_{k}\right) \frac{C_{d} L^{2}}{4} C_{m}^{\alpha},
\end{aligned}
$$

here $v_{\zeta \psi z}=\rho v S_{k}\left(1-\sin \beta_{k}\right) \frac{C_{d} L}{2} C_{z}^{\alpha}$,

$$
v_{\zeta \psi m}=\rho v S_{k}\left(1-\sin \beta_{k}\right) \frac{L}{2} C_{m}^{\alpha}
$$

It is the author's opinion that applying a deduced equation above mentioned resistance factors will allow to solve the tasks of catamaran pitching and heaving when moving with fair speed of Frude number more than 0,3 .

To elaborate the equation of a fast displacement catamaran stabilized with bow and stern stabilizers that include activation possibility we will have to add components of fin stabilizers and the parameters of their activation that are presented in equation (11) $[8,21]$ :

$$
P_{w}=P_{s t}+P_{i n}+P_{c}
$$

where $P_{s t}$-stabilization forces of the wing;

$$
P_{s t}=\left(\frac{\partial C_{y}}{\partial \alpha}\right) \frac{\rho v^{2}}{2} S_{w}\left(\psi-\frac{l_{0} \dot{\psi}}{v}-\frac{\dot{\zeta}_{g}}{v}+\frac{\dot{\zeta}_{0}}{v}\right),
$$

$S_{w}$ - total area of the wing $\left(\mathrm{m}^{2}\right) ; l_{w}$ - distance between fin stabilizers and ship's gravity center $(\mathrm{m})$; $\left(\frac{\partial C_{y}}{\partial \alpha}\right)$ - fin lifting force angular rate; when using active wings, this value considers the effectiveness of stabilizer at the current angle of attack.

Wave profile equation in the area of a fin stabi- lizer is:

$$
\begin{aligned}
& \zeta_{0}=r_{0} e^{-k h} \cos \left(\omega_{k} t+k x\right) ; \\
& \dot{\zeta}_{0}=-\omega r_{0} e^{-k h} \sin \left(\omega_{k} t+k x\right) ;
\end{aligned}
$$

where $h$ - wing depth (m).

$P_{i n}$ - inertia forces on the wing;

$$
P_{\text {in }}=-\Delta M_{w}\left(\ddot{\zeta}_{g}-l_{0} \ddot{\Psi}\right) ;
$$

$P_{c}$ - control forces of the wing;

$$
P_{c}=\left(\frac{\partial C_{y}}{\partial \alpha}\right) \frac{\rho v^{2}}{2} S_{w} \cdot \delta(t)
$$

where $\delta(t)$ - wing put over angle;

$$
\delta(t)=K_{1} \psi+K_{2} \dot{\psi}+K_{3} \ddot{\psi},
$$

here $K_{1}, K_{2}, K_{3}$-stabilizer controlling factors.

$$
\Delta M_{w}=\left(\frac{p \pi \rho}{4}\right) \cdot b \cdot S_{w}
$$

here $p$ - Pabst correction, which will be: for the wings fixed on the ends $p=1$; for the wings not fixed on the ends:

$$
p=\frac{b}{\sqrt{1+(\lambda / b)^{2}}} \cdot\left[1-0.425 \frac{\lambda / b}{1+(\lambda / b)^{2}}\right],
$$

here $b$-chord of the wing (m); $\lambda$ - wing aspect ratio.

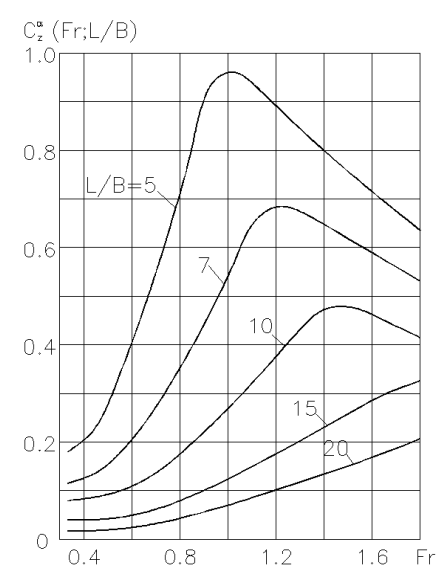

Fig 2. Auxiliary graph for derivative $C_{z}^{\alpha}=d C_{z} / d \alpha$

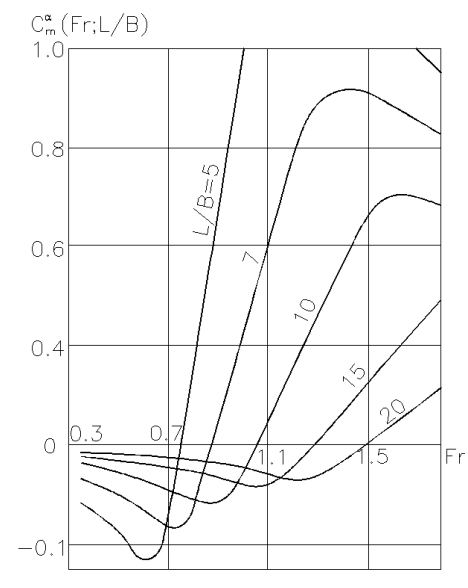

Fig 3. Auxiliary graph for derivative $C_{m}^{\alpha}=d C_{m} / d \alpha$

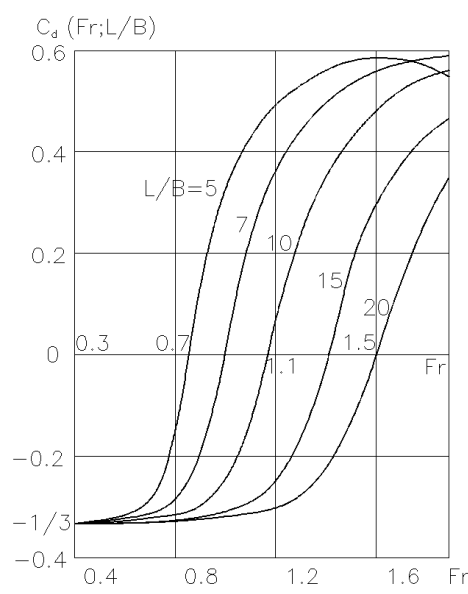

Fig 4. Auxiliary graph for derivative for factor of pressure center $C_{d}$ 
The inertia forces and moments of the wing have relatively small figures comparing to the other components of the equation, but for more objective cal- culation we will include these components of both wings in the equation of a stabilized fast displacement catamaran.

$$
\begin{aligned}
& {\left[\left(\frac{D}{g}+\Delta M+\frac{p \pi \rho}{4}\left(b_{f} S_{f}+b_{a} S_{a}\right)\right) \ddot{\zeta}_{g}+\left(v_{\zeta}+v_{\zeta z}+\frac{\rho v}{2}\left(\frac{\partial C_{y f}}{\partial \alpha} S_{f}+\frac{\partial C_{y a}}{\partial \alpha} S_{a}\right)\right) \dot{\zeta}_{g}+\gamma S_{k} \zeta_{g}+\right.} \\
& \left(\Delta M x_{1}-\frac{p \pi \rho}{4}\left(b_{f} S_{f} l_{f}+b_{a} S_{a} l_{a}\right)\right) \ddot{\psi}+\left(v_{\zeta \psi}+v_{\zeta \psi z}-v \Delta M+\frac{\rho v}{2}\left(\frac{\partial C_{y f}}{\partial \alpha} S_{f} l_{f}+\frac{\partial C_{y a}}{\partial \alpha} S_{a} l_{a}\right)\right) \dot{\psi}+ \\
& \left(\gamma S_{k} l-v v_{\zeta}-v_{\zeta z}-\frac{\rho v^{2}}{2}\left(\frac{\partial C_{y f}}{\partial \alpha} S_{f}+\frac{\partial C_{y a}}{\partial \alpha} S_{a}\right)\right) \psi=r_{0}\left(\gamma a_{0}-\omega^{2} a_{0}^{\prime \prime}-\omega b_{0}^{\prime}\right) \cos \omega_{k} t-r_{0}\left(\gamma b_{0}-\omega^{2} b_{0}^{\prime \prime}-\omega a_{0}^{\prime}\right) \sin \omega_{k} t- \\
& \frac{\rho v}{2} \frac{\partial C_{y f}}{\partial \alpha} S_{f} \omega r_{0} e^{-k h} \sin k l_{f} \cos \omega_{k} t-\frac{\rho v}{2} \frac{\partial C_{y f}}{\partial \alpha} S_{f} \omega r_{0} e^{-k h} \cos k l_{f} \sin \omega_{k} t+\frac{\rho v}{2} \frac{\partial C_{y a}}{\partial \alpha} S_{a} \omega r_{0} e^{-k h} \sin k l_{a} \cos \omega_{k} t+ \\
& \frac{\rho \nu}{2} \frac{\partial C_{y a}}{\partial \alpha} S_{a} \omega r_{0} e^{-k h} \cos k l_{a} \sin \omega_{k} t-\frac{\rho v^{2}}{2} \frac{\partial C_{y f}}{\partial \alpha} S_{f} \delta_{f}(t)-\frac{\rho v^{2}}{2} \frac{\partial C_{y a}}{\partial \alpha} S_{a} \delta_{a}(t) \\
& \left\{\left(I_{y}+\Delta I_{y}+\frac{p \pi \rho}{4}\left(b_{f} S_{f} l_{f}^{2}+b_{a} S_{a} l_{a}^{2}\right)\right) \ddot{\psi}+\left(v_{\psi}+v_{\psi m}+\frac{v^{2}}{\omega^{2}} v_{\zeta}+\frac{\rho v}{2}\left(\frac{\partial C_{y f}}{\partial \alpha} S_{f} l_{f}^{2}+\frac{\partial C_{y a}}{\partial \alpha} S_{a} l_{a}^{2}\right)\right) \dot{\psi}+\right. \\
& \left(D H-v^{2} \Delta M-v v_{\zeta \psi m}-\frac{\rho v^{2}}{2}\left(\frac{\partial C_{y f}}{\partial \alpha} S_{f} l_{f}+\frac{\partial C_{y a}}{\partial \alpha} S_{a} l_{a}\right) \psi+\left(\Delta M x_{1}-\frac{p \pi \rho}{4}\left(b_{f} S_{f} l_{f}+b_{a} S_{a} l_{a}\right)\right) \ddot{\zeta}_{g}+\right. \\
& \left(v_{\zeta \psi}+v_{\zeta \psi m}+v \Delta M+\frac{\rho v}{2}\left(\frac{\partial C_{y f}}{\partial \alpha} S_{f} l_{f}+\frac{\partial C_{y a}}{\partial \alpha} S_{a} l_{a}\right)\right) \dot{\zeta}_{g}+\left(\gamma S_{k} l+v v_{\zeta}\right) \zeta_{g}=r_{0}\left(\gamma a_{1}-\omega^{2} a_{1}^{\prime \prime}-\omega b_{1}^{\prime}\right) \cos \omega_{k} t- \\
& r_{0}\left(\gamma b_{1}-\omega^{2} b_{1}^{\prime \prime}-\omega a_{1}^{\prime}\right) \sin \omega_{k} t-\frac{\rho v}{2} \frac{\partial C_{y f}}{\partial \alpha} S_{f} \omega r_{0} e^{-k h} \sin k l_{f} \cos \omega_{k} t-\frac{\rho v}{2} \frac{\partial C_{y f}}{\partial \alpha} S_{f} \omega r_{0} e^{-k h} \cos k l_{f} \sin \omega_{k} t+ \\
& \frac{\rho v}{2} \frac{\partial C_{y a}}{\partial \alpha} S_{a} \omega r_{0} e^{-k h} \sin k l_{a} \cos \omega_{k} t+\frac{\rho v}{2} \frac{\partial C_{y a}}{\partial \alpha} S_{a} \omega r_{0} e^{-k h} \cos k l_{a} \sin \omega_{k} t+\frac{\rho v^{2}}{2} \frac{\partial C_{y f}}{\partial \alpha} S_{f} l_{f} \delta_{f}(t)+\frac{\rho v^{2}}{2} \frac{\partial C_{y a}}{\partial \alpha} S_{a} l_{a} \delta_{a}(t) .
\end{aligned}
$$

This equation is written for the first time in the theory of fast displacement catamarans. On the left side of this equation the lifting forces on the wing are included and on the right side - the forces of the wave profile near the wing. The equation will allow effective solving of the tasks of pitching and heaving of fast displacement stabilized with fore and aft wings catamaran in regular waves.

Forced oscillations that describe ship's pitching and heaving in a rough sea can be found by the next system of equations [5]:

$$
\begin{aligned}
& \zeta_{g}=\zeta_{1} \cos \omega_{k} t+\zeta_{2} \sin \omega_{k} t, \\
& \psi=\psi_{1} \cos \omega_{k} t+\psi_{2} \sin \omega_{k} t .
\end{aligned}
$$

Combining equation (19) with (20) after some mathematical transformations, solving the system of four algebraic equations we will get the decision of the problem of stabilized catamaran pitching and heaving in regular waves $\zeta_{1}, \zeta_{2}, \psi_{1}$ and $\psi_{2}$ as time functions.

Having found $\zeta_{1}, \zeta_{2}, \psi_{1}$ and $\psi_{2}$ the system of equations (20) can be presented in a monomial type:

$$
\begin{gathered}
\zeta_{g}=\zeta_{g m} \cos \left(\omega_{k} t-\varepsilon_{\zeta}\right), \\
\psi=\psi_{m} \cos \left(\omega_{k} t-\varepsilon_{\psi}\right) .
\end{gathered}
$$

as well as the amplitudes of pitching and heaving of stabilized catamaran:

$$
\begin{gathered}
\zeta_{g m}=\sqrt{\zeta_{1}^{2}+\zeta_{2}^{2}}, \\
\psi_{m}=\sqrt{\psi_{1}^{2}+\psi_{2}^{2}} .
\end{gathered}
$$

and their starting phases:

$$
\begin{aligned}
& \varepsilon_{\zeta}=\operatorname{arctg} \frac{\zeta_{1}}{\zeta_{2}}, \\
& \varepsilon_{\psi}=\operatorname{arctg} \frac{\psi_{1}}{\psi_{2}} .
\end{aligned}
$$

Dividing the left sides of the equation (22) on wave amplitude $r_{0}$, as well as the equation (23) on 
angle amplitude of wave slope $\alpha_{0}$, we will get the expressions for pitching and heaving amplification factors for the stabilized catamaran moving against waves.

Having the amplification factors for the stabilized catamaran in regular waves we can define its pitching and heaving parameters when moving in rough sea. To do so it is necessary to assign spectral density of the wave ordinates, for example, as in formula (25) [5]:

$$
\begin{aligned}
& S_{\zeta}(h, \omega)=\frac{0,2596}{\omega_{m}(h)} h^{2}\left(\frac{\omega_{m}(h)}{\omega}\right)^{6} \cdot \exp \left[-1,5\left(\frac{\omega_{m}(h)}{\omega}\right)^{4}\right]+ \\
& \frac{0,00565}{\omega_{m}(h)} h^{2}\left(\frac{\omega_{m}(h)}{\omega}\right)^{8} \cdot \exp \left[-0,48\left(\frac{\omega_{m}(h)}{\omega}\right)^{4}\right],
\end{aligned}
$$

where $\omega_{m}(h)=1,42 \cdot h^{-0.45}$ - frequency, corresponding maximum of the spectrum $(\mathrm{rad} \cdot \mathrm{m} / \mathrm{s})$.

Therefore we can calculate dispersions of angles $\psi$ and ordinates $\zeta_{g}$ as follows:

$$
\begin{aligned}
& D_{\zeta_{g}}=\int_{0}^{\infty}\left(\frac{\zeta_{g m}}{r_{0}}\right)^{2} \cdot S_{\zeta}(h, \omega) \cdot d \omega ; \\
& D_{\psi}=\int_{0}^{\infty}\left(\frac{\psi_{m}}{\alpha_{0}}\right)^{2} \frac{\omega^{4}}{g^{2}} \cdot S_{\zeta}(h, \omega) \cdot d \omega,
\end{aligned}
$$

and average amplitudes and $3 \%$ probability amplitudes:

$$
\begin{gathered}
\bar{\zeta}_{g m}=1,25 \sqrt{D_{\zeta_{g}}}, \quad \zeta_{g m 3 \%}=2,64 \sqrt{D_{\zeta_{g}}}, \\
\bar{\psi}_{m}=1,25 \sqrt{D_{\psi}}, \quad \Psi_{m 3 \%}=2,64 \sqrt{D_{\psi}} .
\end{gathered}
$$

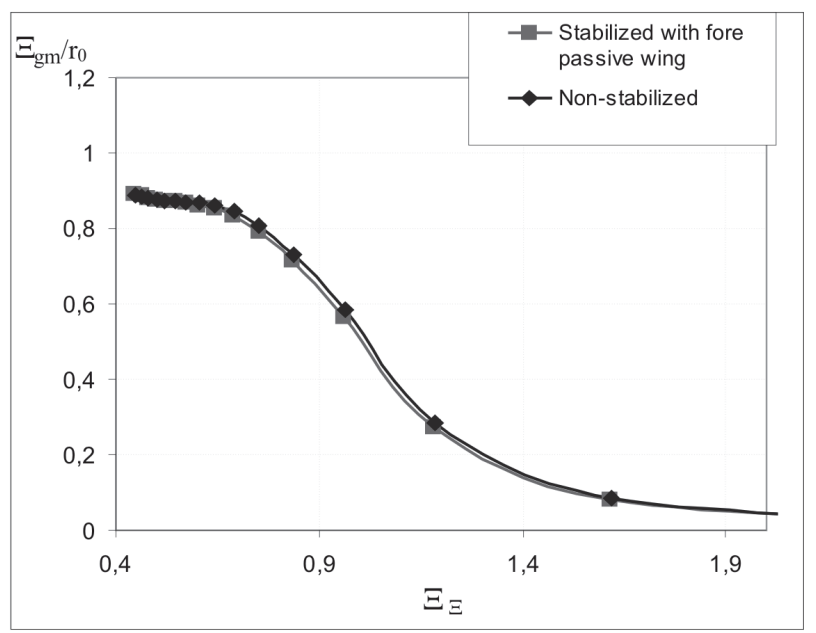

Fig 5. Heaving gain-frequency characteristic of fast displacement stabilized and not stabilized catamaran in regular waves

\section{Results}

Using the developed method for evaluating pitching and heaving of a fast displacement stabilized catamaran, pitching and heaving characteristics were calculated (Figs 5,6) for a small fishing catamaran and compared to data from model tests of the same catamaran to scale of 1:12 in irregular waves [22].

Dimensions of a catamaran and its model are presented in Table 1.

In Fig 7 deck pouring curves of a calculated stabilized catamaran are presented where we can see how the waves are interfering with the ship. And in Fig 8 the catamaran movement character in the same 50 meters length waves is presented.

Table 1. Dimensions of catamaran and its model

\begin{tabular}{|l|c|c|}
\hline \multicolumn{1}{|c|}{ Dimensions } & Catamaran & Model \\
\hline $\begin{array}{l}\text { Length on level of load } \\
\text { waterline, } \mathrm{m}\end{array}$ & 23,5 & 1,964 \\
\hline Breadth of one hull, $\mathrm{m}$ & 4,25 & 0,354 \\
\hline \multicolumn{1}{|c|}{$\delta$} & 1,85 & 0,154 \\
\hline \multicolumn{1}{|c|}{$\alpha$} & \multicolumn{2}{|c|}{0,632} \\
\hline Calculation draft, $\mathrm{c}$ & \multicolumn{2}{|c|}{0,85} \\
\hline \multicolumn{1}{|c|}{0,98} \\
\hline Area of the wing, $\mathrm{m}^{2}$ & 1,176 & 0,098 \\
\hline $\begin{array}{l}\text { Distance between midship } \\
\text { and wing, m }\end{array}$ & 9 & 0,75 \\
\hline Depth of the wing, $\mathrm{m}$ & 2,6 & 0,2167 \\
\hline Type of the wing & Flat Naca 0015 \\
\hline Horizontal clearance, $\mathrm{m}$ & 3 & 0,25 \\
\hline Vertical clearance, $\mathrm{m}$ & 1,32 & 0,11 \\
\hline Azimuth, deg. & \multicolumn{2}{|c|}{$180^{\circ}$} \\
\hline Frude number & \multicolumn{2}{|c|}{0,276} \\
\hline
\end{tabular}

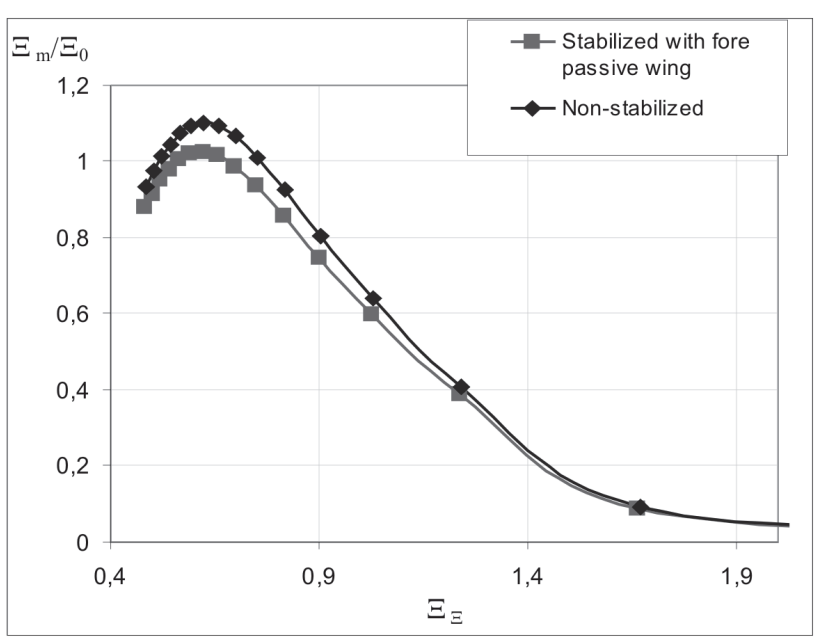

Fig 6. Pitching gain-frequency characteristic of fast displacement stabilized and not stabilized catamaran in regular waves 


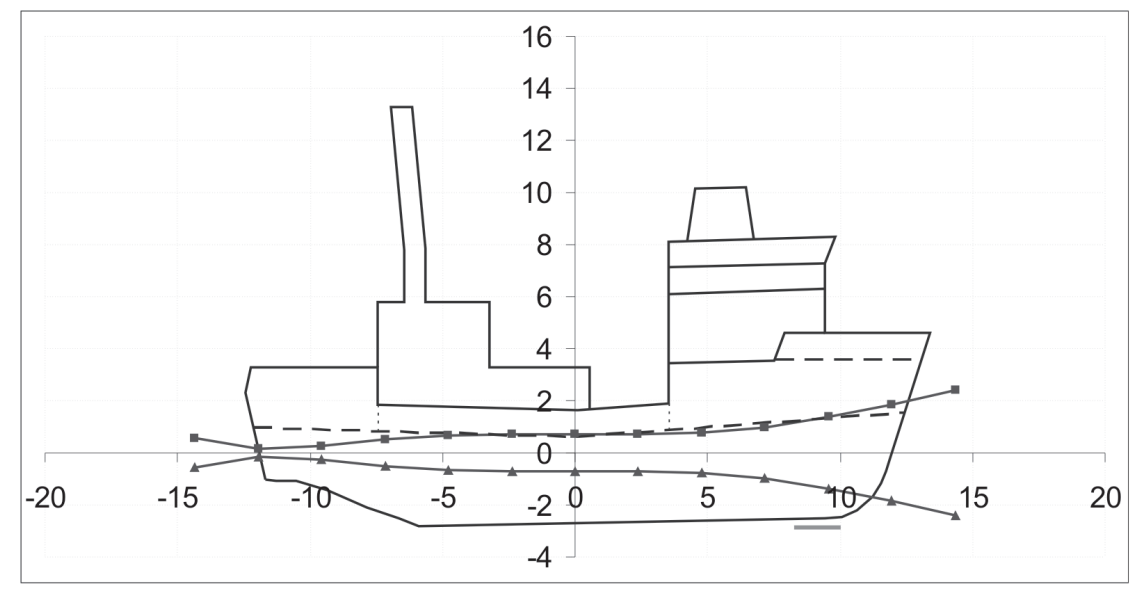

Fig 7. Deck pouring curves of a calculated stabilized catamaran in regular 50 meters length waves

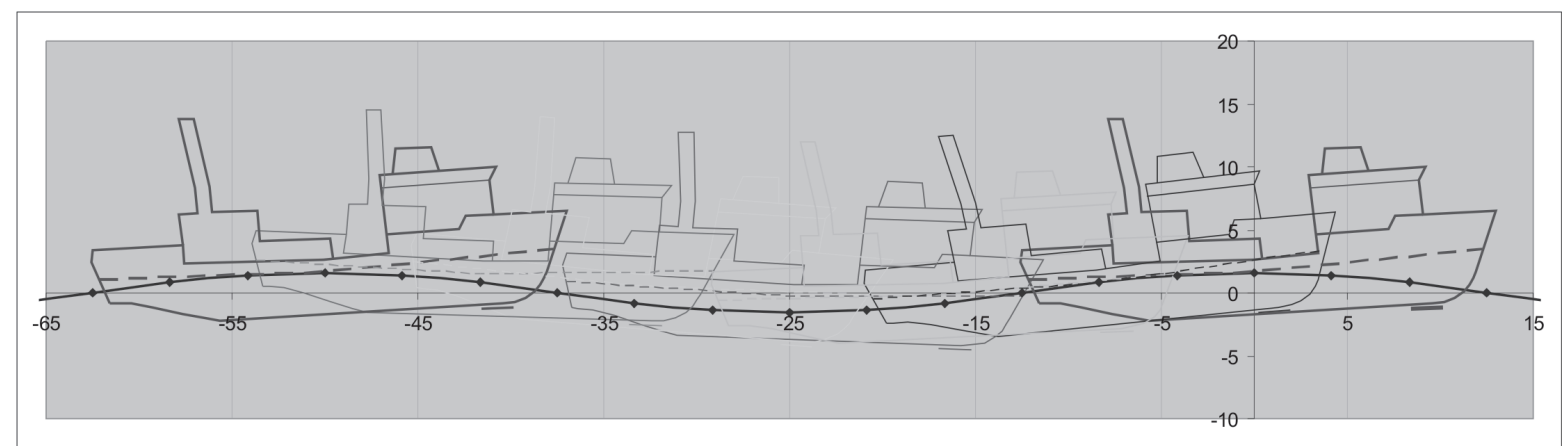

Fig 8. Stabilized catamaran movement character in regular 50 meters length waves

From gain-frequency characteristics presented in Figs 5, 6 it is clearly seen that a fore passive wing is more effective in reduction of pitching than heaving. Having these characteristics we can evaluate pitching amplitudes and heaving angles in irregular seas and compare calculation results with the data of model tests presented in [22].

Comparing of the calculation results with the data of model tests is presented in Table 2.

Table 2. Comparing of the calculation with the data of model tests

\begin{tabular}{|c|c|c|}
\hline Compared characteristics & $\begin{array}{c}\text { Calculation } \\
\text { results }\end{array}$ & $\begin{array}{c}\text { Model } \\
\text { tests }\end{array}$ \\
\hline Average pitch angles, deg. & 3,17 & 3,72 \\
\hline $3 \%$ probability angles, deg. & 6,70 & 7,45 \\
\hline
\end{tabular}

\section{Conclusions}

Corresponding to the received heaving and pitching gain-frequency characteristics of a displacement stabilized and not stabilized catamaran in regular waves we can make the following conclusions:
1. Using fore passive wings as stabilizers for a catamaran essentially reduces pitching and heaving amplitudes.

2. The largest effectiveness of fore fin stabilizers is in the most negative pitching and heaving area, in the area of resonance frequency or near it.

3. The above presented calculation method of a fast displacement catamaran equipped with bow fin stabilizers pitching and heaving in a rough sea could be effectively applied in these areas:

- In a design stage of a catamaran evaluating its pitching and heaving and determining the effectiveness of standard fin stabilizers or designing a better one suitable to the exact project;

- In a design stage of fin stabilizers for already existing catamaran, evaluating pitching and heaving of a stabilized catamaran and determining the effectiveness of a designed fin stabilizer;

- As a helping tool for the captain of a catamaran when using fin stabilizers with adjustable 
angle of attack giving ability to choose the optimal fin angle to have the least ship motion in a rough sea.

Corresponding to the received comparing results of a displacement stabilized catamaran in irregular waves we can make the following conclusions:

1. The qualitative results of calculation are in good correspondence with model tests from which we can conclude that the elaborated method is trustful and can be applied in the design of catamarans as stated above.

2. The quantitative results of calculation are not in good correspondence because of these reasons:

- The spectra of irregular waves is not presented in the article [24], therefore we can not directly replay exactly all conditions of model tests.

- There could be inaccuracy of measurements during model tests.

\section{References}

1. Dubrovskiy, V. A. Large fast multi-hulls: making a correct comparison and design. The Naval Architect, No 11, London: The Royal Institution of Naval Architects, 2001, p. 30-31.

2. Dubrovskiy, V. A. Attractive potential of multi-hulls. The Naval Architect, No 9, London: The Royal Institution of Naval Architects, 1997, p. 18-19.

3. Kogan, E. M. To the calculation of main part of disturbing forces for oscillating catamaran in liquid of finite depth. In: Proceedings of Nikolaev Shipbuilding Institute of adm. S. O. Makarov. Ships theory (Труды НКИ. Теория корабля), Vol 44, Nikolaev: Shipbuilding Institute of adm. S. O. Makarov, 1971, p. 42-45 (in Russian).

4. Kogan E. M. To hydrodinamical theory of oscillations of catamaran in liquid of finite depth. In: Proceedings of Nikolaev Shipbuilding Institute of adm. S. O. Makarov. Ships theory (Труды НКИ. Теория корабля), Vol 35, Nikolaev: Shipbuilding Institute of adm. S. O. Makarov, 1970, p. 33-39 (in Russian).

5. Lougovsky, V. V. Ship Oscillations (Качка корабля). Sankt-Peterburg: State Marine Technical University, 1999. 425 p. (in Russian).

6. Rawsonm, K. J.; Tupper, E. C. Basic Ship Theory, Vol 1\&2, Essex: Longman Scientific \& Technical, 1993. 375, $702 \mathrm{p}$.

7. Pursey, H. J. Merchant ship stability. Glasgow: Broun, Son \& Ferguson, Ltd., 1996. 209 p.

8. Cholodilin, A. N.; Shmyriov, A. N. Seakeeping and ship stabilization in rough sea (Мореходность и стабилизация судов на волнении). Leningrad: Shipbuilding, 1976. 328 p. (in Russian).

9. Bertram, V. Practical ship hydrodynamics. Oxford: Linacre House, 2002. 270 p.

10. Cholodilin, A. N. Ship stabilization in rough sea
(Стабилизация судна на волнении). Leningrad: Shipbuilding, 1973. 232 p. (in Russian).

11. Borodaj, I. K.; Morenshildt, V. A. and etc. Application tasks of ship dynamics in rough sea (Прикладные задачи динамики судов на волнении). Leningrad: Shipbuilding, 1989. 264 p. (in Russian).

12. Dubrovskiy, V. A. Creation problems of multihull ships on international conference FAST'01. Shipbuilding (Судостроение), No 1, Sankt-Peterburg: Shipbuilding, 2002, p. 17-19 (in Russian).

13. Kornev, N. V.; Nesterova, A. V.; Mizhott, G.; Hoppe, K. G. Design of catamarans with hydrodynamic relief the help of nonlinear discontinuous whirlwind method. Shipbuilding (Судостроение), No 4, Sankt-Peterburg: Shipbuilding, 2001, p. 12-14 (in Russian).

14. Kogan, E. M. To the question of catamaran oscillations in oblique waves. In: Proceedings of Nikolaev Shipbuilding Institute of adm. S. O. Makarov. Ships theory and hydromechanics (Труды НКИ. Теория корабля и гидромеханика), Vol 74, Nikolaev: Shipbuilding Institute of adm. S. O. Makarov, 1973, p. 27-30 (in Russian).

15. Mastushkin, U. M. Theoretical analysis of moderation of catamaran longitudinal oscillations with the help of underwater wing. In: Proceedings of Kaliningrad Technical Institute of Fish Industry. Hydromechanics and hydraulics (Труды КТИПРХ. Гидромеханика и гидравлика), Vol 43, Kaliningrad: Kaliningrad Technical Institute of Fish Industry, 1972, p. 19-23 (in Russian).

16. Belenky, L. M. and etc. Catamarans "Experiment" (Катамараны «Эксперимент»). Leningrad: Shipbuilding, 1979. 132 p. (in Russian).

17. Dubrovskiy, V. A.; Sokolov, V. P. What to be ferry SanktPeterburg - Helsinki? Shipbuilding (Судостроение), No 3, Sankt-Peterburg: Shipbuilding, 2002, p. 11-16 (in Russian).

18. Cariov, B. A.; Sokolov, V. P. Design aspects of hydrodynamic perfection of fast vessels. Sea bulletin (Морской вестник), No 1(1), Sankt-Peterburg: State Marine Technical University, 2002, p. 49-56 (in Russian).

19. Voitkunsky, J. I. Reference book of ship theory. Ship statics. Ship oscillations (Справочник по теории корабля. Статика судов. Качка судов). Leningrad: Shipbuilding, 1985. 440 p. (in Russian).

20. Alferjev, M. J.; Madorsky, G. S. Inland water transport catamarans (Транспортные катамараны внутреннего плавания). Moscow: Transport, 1976. 336 p. (in Russian).

21. Shmyriov, A. N. and etc. Ship oscillation stabilizers (Успокоители качки судов). Leningrad: Shipbuilding, 1972. 480 p. (in Russian).

22 Mastushkin, U. M.; Obrecht, V. S. Experimental study of longitudinal oscillations of catamaran on self-propelled models. In: Proceedings of Science Technical Society of Ship Industry of Acad. A. N. Krylov (Материалы по обмену опытом НТО Судпрома им. ак. А. И. Крылова), Vol 173, Leningrad: Shipbuilding, 1972, p. 89-95 (in Russian). 